\title{
Projetando uma aplicação para apoiar o ensino de inglês a partir de uma experiência de uso
}

\author{
Thiago Hellen O. da Silva ${ }^{1}$, Micael Maia Ferreira ${ }^{1}$, Jeferson da Silva Juliani ${ }^{1}$, \\ Gabriel Fonseca de O. Júnior ${ }^{1}$, Marília Soares Mendes ${ }^{1}$ \\ ${ }^{1}$ Universidade Federal do Ceará (UFC) - Campus Russas \\ R. Felipe Santiago, N 411, Cidade Universitária, Russas - CE - Brasil \\ \{thiagoo360, micaelmf, jeferson.engsoftware, gabrieljunior\}@alu.ufc.br, \\ marilia.mendes@ufc.br
}

\begin{abstract}
Technology has supported teachers in many areas. The design of educational software involves the knowledge of the context of use in which it will be inserted. However, software design techniques do not always focus on engaging their target users. This article presents the project of an application to support educators in English teaching. The project was developed using a participatory design methodology that suggests the use experience as a way of collecting and exploring ideas to design a system. A high-fidelity prototype was produced and evaluated. As results, the process of building the application from the initial ideas to the perceptions of users' use.
\end{abstract}

Resumo. A tecnologia tem apoiado professores em diversas áreas. O projeto de softwares educativos envolve o conhecimento do contexto de uso em que ele será inserido. No entanto, nem sempre as técnicas de projeto de softwares focam no envolvimento de seus usuários-alvo. Este artigo apresenta o projeto de uma aplicação para apoiar professores no ensino de inglês. O projeto foi desenvolvido utilizando uma metodologia de design participativo que sugere a experiência de uso como forma de coleta e exploração de ideias para projetar um sistema. Um protótipo de alta fidelidade foi produzido e avaliado. Como resultados, apresenta-se o processo de construção do aplicativo desde as ideias iniciais até as percepções finais dos usuários, depois do aplicativo estar pronto.

\section{Introdução}

A tecnologia vem sendo amplamente utilizada com o propósito de apoiar o ensino [Tomlinson et al. 2016, Nascimento et al. 2017, Abreu et al. 2017]. Tomlinson et al. (2016) sugerem a inclusão de aplicativos para auxiliar no processo de ensinoaprendizagem, de modo a incentivar os alunos a aprenderem mais sobre os conteúdos vistos em sala de aula. A inserção da tecnologia como apoio ao professor vem sendo usada em diversas áreas de ensino. Toledo (2015) analisou a contribuição de softwares educacionais e apontou que seu uso tem proporcionado avanços pedagógicos, sendo capazes de proporcionar melhorias significativas na educação e desenvolvimento dos alunos.

Neste contexto, um projeto de extensão foi iniciado em 2017 na cidade de Russas (CE), com foco no desenvolvimento de softwares educativos para a comunidade, principalmente de escolas públicas. Para alcançar o objetivo mencionado, os participantes do 
VII Congresso Brasileiro de Informática na Educação (CBIE 2018)

Anais do XXIX Simpósio Brasileiro de Informática na Educação (SBIE 2018)

projeto, autores deste artigo, realizaram uma entrevista com a coordenadora curricular da secretaria de educação do município. Nessa entrevista, foi relatado que os alunos da rede pública municipal têm aulas de língua inglesa apenas a partir dos 10 anos de idade, ou seja, quando já estão no ensino fundamental 2 (6 ao 9 ano). Além disso, a secretaria enfrenta dificuldade para encontrar profissionais capacitados a lecionar essa disciplina, colocando professores, independente do seu perfil acadêmico, para lecioná-la. Para isso, esses professores buscam recursos tecnológicos que possam apoiá-los na realização de seu trabalho. Apesar dessas dificuldades, o município tem interesse em oferecer o ensino de inglês para turmas a partir do 2 ano do ensino fundamental, quando a maioria dos alunos já sabem ler e têm entre 6 e 7 anos de idade. Também foi relatado que em todas as escolas há um laboratório de informática a disposição, para uso pedagógico.

Desta forma, o projeto focou no desenvolvimento de um software de apoio ao ensino da língua inglesa para alunos de escolas públicas a partir do 2 ano do ensino fundamental, considerando que alguns estudos relatam sobre o aprendizado de uma nova língua se tornar desafiador à medida que a idade avança e reforçam a necessidade do contato com outros idiomas nos primeiros anos de vida [Deliberato 2016].

No entanto, o projeto de softwares educativos envolve o conhecimento do contexto educacional em que professores e alunos, fazem parte. É importante considerar: fatores éticos, sociais e ambientais, que influenciam no uso e são difíceis de identificar sem um entendimento detalhado do sistema. Para o entendimento do contexto educacional, vê-se a necessidade de uso de novas técnicas que permitam trabalhar com tecnologia no sentido de auxiliar profissionais a focarem em aspectos da interação desde as fases iniciais do processo de desenvolvimento.

Este trabalho utiliza uma metodologia para o levantamento de requisitos e o design da interação de um software de apoio aos profissionais de escolas públicas no ensino da língua inglesa para alunos com idade a partir de 6 anos. Para o projeto foram consideradas tanto as experiências dos usuários quanto da equipe de desenvolvimento. Foram realizados estudos de softwares similares, visitas em escolas do município, conversa com os professores e uma experiência de uso com os alunos a fim de levantar requisitos para o software. Como resultados, foi desenvolvido um protótipo e avaliado. Este artigo está organizado da seguinte forma: na próxima seção são mostrados alguns trabalhos relacionados; em seguida, é apresentada a metodologia utilizada neste estudo, demonstrado o projeto do software proposto; por fim, o software é apresentado e mostrada sua avaliação, seguida de uma discussão, conclusão e trabalhos futuros.

\section{Trabalhos Relacionados}

Nascimento et al. (2017) propuseram um aplicativo chamado Storyteller. Este aplicativo tem o objetivo de diminuir as dificuldades do ensino da língua inglesa para crianças de 5 a 7 anos, utilizando histórias animadas e contadas em inglês. As atividades são divididas em dois níveis, A e B. O nível A corresponde às noções e regras básicas da língua inglesa. No nível B são apresentadas as estruturas de linguagem e leitura. Para algumas atividades, é necessário que alguém fixe alguns códigos QRs (Quick Response) em locais específicos, para que, quando escaneados por um smartphone, reproduzam histórias relacionadas ao lugar em que o código foi fixado. Os professores também podem interagir no Storyteller realizando o cadastro de turmas e alunos, além de acompanhar, por meio de gráficos, o 
VII Congresso Brasileiro de Informática na Educação (CBIE 2018)

Anais do XXIX Simpósio Brasileiro de Informática na Educação (SBIE 2018)

aprendizado dos alunos. Apesar deste estudo apresentar um aplicativo para auxiliar o ensino de inglês às crianças, ele necessita que algum responsável deixe fixado códigos QRs nos locais pré-definidos, e também não possibilita a inclusão de novos lugares.

No trabalho de Santana e Ferreira (2017) é abordada uma experiência realizada por alunos do $5^{\circ}$ ano do Ensino Fundamental de uma escola privada durante as aulas de inglês. A experiência consistiu no desenvolvimento de um jogo para ampliar o vocabulário dos alunos, além de ensinar o uso correto de verbos em inglês utilizando o tema Sustentabilidade do Planeta [Santana and Ferreira 2017]. O jogo foi desenvolvido utilizando o software Constructor, que é um editor de jogos destinados a não-programadores. Para o desenvolvimento do jogo, a turma foi dividida em nove duplas onde cada dupla foi desafiada a desenvolver um jogo de acordo com a sua escolha. Após a conclusão do desenvolvimento, as duplas compartilharam o que desenvolveram com seus colegas a fim de testá-los. Ao final do projeto, os jogos foram disponibilizados para a comunidade escolar. Contudo, cada aplicativo é direcionado ao ensino de um determinado conteúdo da língua inglesa, o que tornaria inviável a sua utilização contínua em sala de aula, visto que foram desenvolvidas diferentes aplicações.

Os autores Abreu et al. (2017) apresentam o projeto Fantastic Pirates composto por dois aplicativos: Fantastic Pirates (FP) e Fantastic Pirates Educator (FPE). O FP é um aplicativo móvel destinado a crianças de até 10 anos e tem como tema "piratas" [Abreu et al. 2017]. Nele, as crianças aprendem algo novo de forma lúdica e divertida, por meio de questionários. Os questionários são criados por seus pais ou professores, e para isso, eles devem utilizar o aplicativo FPE. Com o FPE, além de criar questionários, é possível acessar um relatório de acertos e erros para cada respondente do questionário. Apesar de o Fantastic Pirates permitir a personalização do conteúdo por pais e professores, seu uso é limitado aos questionários criados, ou seja, para que uma criança realize uma atividade, ela deve saber o código referente ao questionário que deseja responder, não sendo possível escolhê-lo em lista de atividades.

\section{Metodologia}

Para construir o projeto do software, foi utilizada uma metodologia de Design da Interação e levantamento de Requisitos com foco na Comunicação e Exploração de ideias, denominada DIRCE [Mendes 2009, Mendes and Furtado 2014]. Esta metodologia foi escolhida por envolver projetistas e usuários no processo do projeto de interação de um sistema. A metodologia sugere que o software seja projetado a partir de uma experiência de uso com os futuros usuários do sistema [Mendes 2009, Mendes and Furtado 2014]. A DIRCE (Figura 1) é constituída das seguintes etapas: (1) Estudo de aplicações semelhantes; (2) Experiência de uso; (3) Identificação dos requisitos do sistema; (4) Definição e aplicação de pré-padrões e; (5) Definição do projeto de interação, explicadas nos próximos parágrafos.

$\mathrm{Na}$ primeira etapa, é indicada a técnica análise de competidores com o objetivo identificar pontos fortes e fracos de soluções semelhantes já existentes, possibilitando o conhecimento sobre o que já existe no mercado [Cybis et al. 2015]. Na segunda etapa, é realizada uma experiência de uso, com a execução de quatro passos: a) seleção dos participantes; b) preparação da experiência; c) aplicação da experiência; e, d) reunião pósexperiência. A seleção dos participantes envolve contactar usuários com o perfil esperado 
VII Congresso Brasileiro de Informática na Educação (CBIE 2018)

Anais do XXIX Simpósio Brasileiro de Informática na Educação (SBIE 2018)

do projeto. Em seguida, é recomendado proporcionar uma experiência do futuro software a eles. Essa experiência envolve uma preparação, com a construção de um protótipo de baixa fidelidade, a utilização do protótipo pelos participantes e, após a experiência, os projetistas relatam suas percepções quanto ao uso.

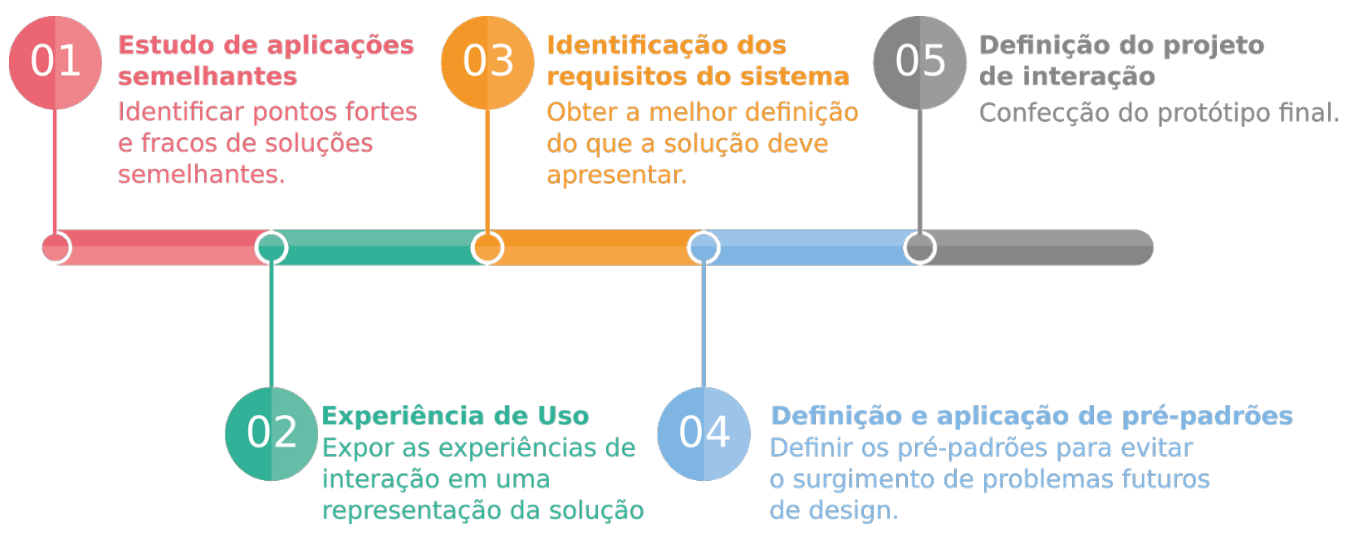

Figura 1. Metodologia DIRCE

$\mathrm{Na}$ terceira etapa, os requisitos são definidos a partir dos estudos realizados. $\mathrm{Na}$ quarta etapa, são definidos e aplicados pré-padrões baseando-se nos resultados das etapas anteriores. Pré-padrões são padrões não validados, obtidos a partir da observação de uma experiência de uso, com o objetivo de evitar o surgimento de problemas no design da solução [Chung et al. 2004]. Por fim, na quinta etapa, têm-se a definição do projeto de interação, com construção de um protótipo funcional. Na próxima seção, tais etapas serão melhor detalhadas, descrevendo a construção do projeto.

\section{Projeto da aplicação}

\subsection{Estudo de aplicações semelhantes}

Foram estudados os aplicativos: Busuu Kids ${ }^{1}$, Duolingo ${ }^{2}$, Fun English ${ }^{3}$, e Hello English ${ }^{4}$. Tais aplicativos foram escolhidos por terem o objetivo de ensinar inglês e serem populares na categoria Educação, nas lojas de aplicativos.

A Tabela 1 apresenta uma análise dos aplicativos estudados, de acordo com os aspectos: disponibilidade na web; disponibilidade para dispositivos móveis; crianças como principais usuários; possibilidade de refazer as atividades; possibilidade de interagir com outros usuários; permite o uso em instituições de ensino; e permite a personalização das atividades por um professor. Estes aspectos foram obtidos a partir de uma conversa realizada com professores de língua inglesa.

Foi observado que apenas o Busuu Kids e o Duolingo têm disponibilidade na web e em dispositivos móveis. Apesar do Duolingo possibilitar a interação com outros usuários e ser usado por instituições escolares, seu principal público-alvo não são crianças. Nenhum dos aplicativos estudados possibilita que as atividades sejam personalizadas por professores.

\footnotetext{
${ }^{1}$ Busuu for Kids. Disponível em: https://www.busuu.com/en/kids Acessado em 16 de março de 2018.

${ }^{2}$ Duolingo. Disponível em: https://www.duolingo.com/ Acessado em 16 de março de 2018.

${ }^{3}$ Fun English. Disponível em: http://studycat.net/apps/fun-english/ Acessado em 16 de março de 2018.

${ }^{4}$ Hello English. Disponível em: http://new.culturealley.com Acessado em 16 de março de 2018.
} 
VII Congresso Brasileiro de Informática na Educação (CBIE 2018)

Anais do XXIX Simpósio Brasileiro de Informática na Educação (SBIE 2018)

Tabela 1. Comparativo das aplicações semelhantes

\begin{tabular}{|l|c|c|c|c|c|}
\hline \multicolumn{1}{|c|}{ Critérios avaliados } & $\begin{array}{c}\text { Busuu } \\
\text { Kids }\end{array}$ & Duolingo & $\begin{array}{c}\text { Fun } \\
\text { English }\end{array}$ & $\begin{array}{c}\text { Hello } \\
\text { English }\end{array}$ & $\begin{array}{c}\text { Aplicação } \\
\text { proposta }\end{array}$ \\
\hline Disponibilidade na web & $\mathrm{X}$ & $\mathrm{X}$ & & & $\mathrm{X}$ \\
\hline $\begin{array}{l}\text { Disponibilidade para } \\
\text { dispositivos móveis }\end{array}$ & $\mathrm{X}$ & $\mathrm{X}$ & $\mathrm{X}$ & $\mathrm{X}$ & $\mathrm{X}$ \\
\hline $\begin{array}{l}\text { Crianças como principais } \\
\text { usuários }\end{array}$ & $\mathrm{X}$ & & $\mathrm{X}$ & $\mathrm{X}$ & $\mathrm{X}$ \\
\hline $\begin{array}{l}\text { Possibilidade de refazer } \\
\text { atividades }\end{array}$ & $\mathrm{X}$ & $\mathrm{X}$ & $\mathrm{X}$ & $\mathrm{X}$ & $\mathrm{X}$ \\
\hline Interação com outros usuários & & $\mathrm{X}$ & & & $\mathrm{X}$ \\
\hline Uso por instituições escolares & & $\mathrm{X}$ & & & $\mathrm{X}$ \\
\hline Personalização pelo professor & & & & & $\mathrm{X}$ \\
\hline
\end{tabular}

\subsection{Projeto do software a partir de uma experiência de uso}

a) Seleção dos participantes: os participantes da experiência de uso foram: 32 alunos de uma escola municipal; a professora da turma; e, dois dos autores deste artigo. Os alunos participantes tinham idades entre 6 e 7 anos e eram estudantes de uma turma do 2 ano do ensino fundamental. Esta turma foi escolhida por não ter aulas de língua inglesa. Os autores exerceram os papéis de aplicador (guiando a experiência de uso) e observador (observando a interação) durante a experiência. Para esta experiência de uso, o projeto passou por um comitê de ética da universidade. Para seleção dos participantes foi enviado um termo de consentimento livre e esclarecido para ser assinado pelos pais das crianças, autorizando sua participação na experiência de uso.

b) Preparação da experiência: nesta etapa foram utilizados os seguintes materiais: protótipo de baixa fidelidade, computador, projetor de slides e folha de respostas. $\mathrm{O}$ protótipo de baixa fidelidade foi elaborado utilizando a ferramenta de apresentações do Google. Uma das telas do protótipo é apresentada na Figura 2. O protótipo foi mostrado utilizando um projetor de slides e para que todos pudessem interagir, foi entregue uma folha de respostas para as atividades propostas durante a experiência. Um exemplo da folha de respostas pode ser observado na Figura 2.
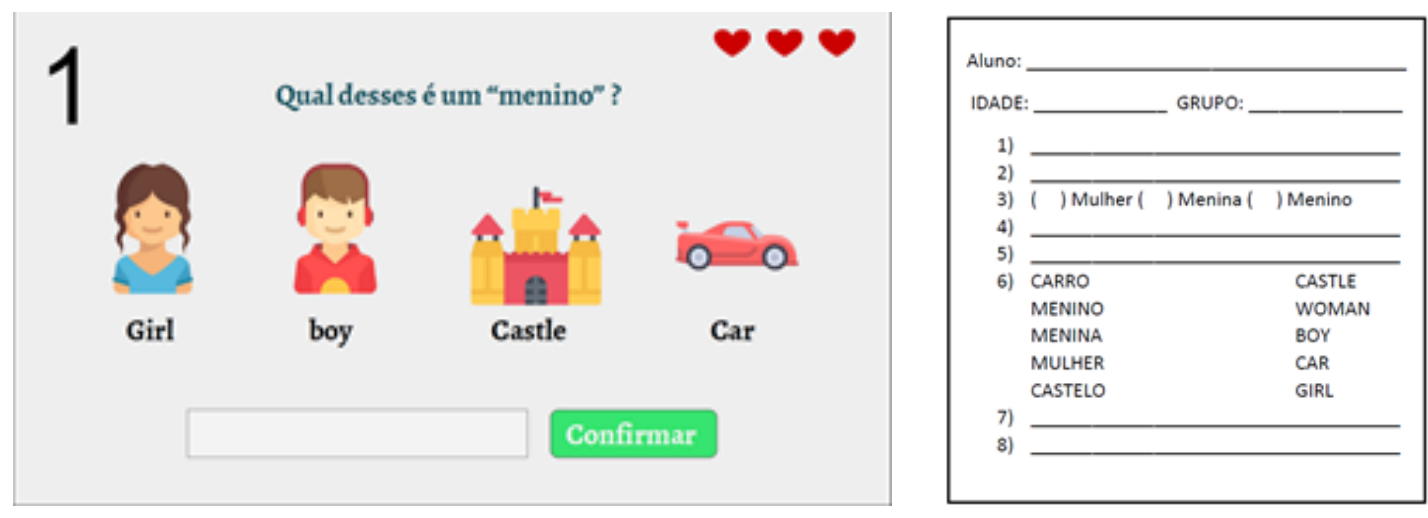

Figura 2. Projeção do protótipo utilizado e folha de respostas utilizada

c) Aplicação da experiência: a experiência de uso (Figura 3) foi realizada de 
VII Congresso Brasileiro de Informática na Educação (CBIE 2018)

Anais do XXIX Simpósio Brasileiro de Informática na Educação (SBIE 2018)

forma similar a um jogo de memória, onde os alunos deveriam estar atentos às atividades para identificar a resposta correta e lembrá-la posteriormente. Ao início, a turma foi dividida em grupos com o auxílio da professora.

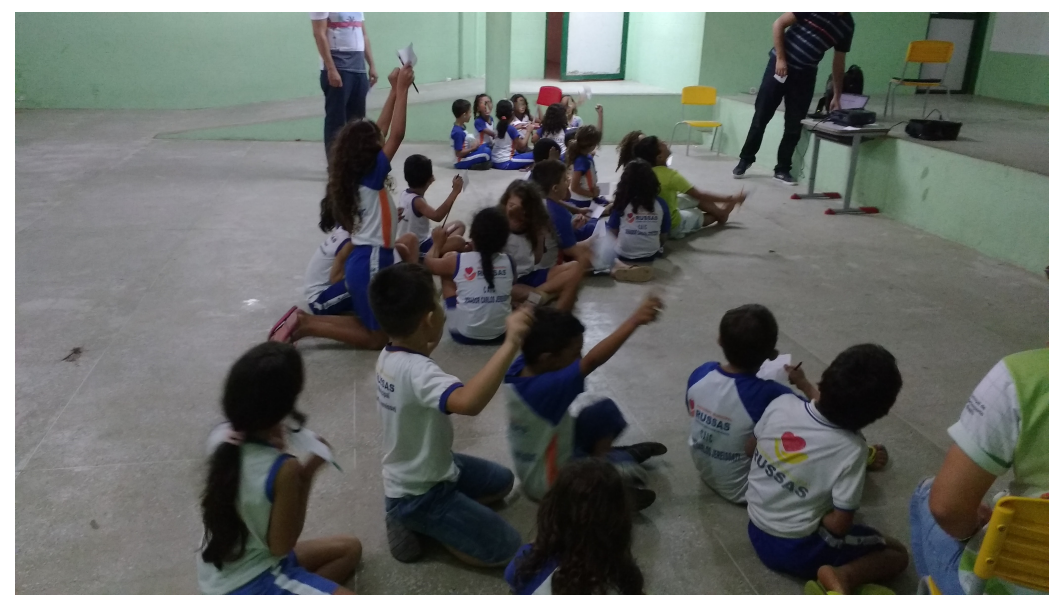

Figura 3. Aplicação da experiência

Foi contada a seguinte história com contexto medieval para que os alunos pudessem adentrar no mundo de fantasias: Paulo Silva é um camponês que vive em um pequeno vilarejo onde todas as pessoas falam apenas a língua portuguesa. Ele leva uma vida muito simples ajudando seu pai a cultivar as terras da família. Paulo está crescendo e sentindo a necessidade de conhecer os lugares das histórias que seu avô tanto contava. Certo dia, Paulo não parava de pensar nas histórias de seu avô. Em sua imaginação existia um mundo de fantasias. Neste mesmo dia, sentado em um barranco próximo a sua casa, Paulo decide que ele precisava viver suas próprias aventuras, descobrir o mundo, para que um dia tivesse histórias para contar, assim como seu avô. No dia seguinte, confiante de sua decisão, pega suas coisas, despediu-se da sua família e foi em busca de novas aventuras. Após alguns dias de caminhada, ele chegou a um reino muito bonito chamado English Kingdom. Porém uma coisa chamou a atenção de Paulo: as pessoas falavam uma língua diferente, era a língua inglesa. Paulo gostou tanto daquela maneira de falar que resolveu ficar alguns dias para aprender Inglês. Ele não sabia, mas a sua aventura estava apenas começando! Vamos emergir no mundo de Paulo?

Em seguida, foram feitas oito perguntas, sendo exibidas no projetor de slides. Algumas perguntas eram de múltipla-escolha e outras com uma imagem ilustrando a opção questionada. Após cada pergunta, os aplicadores da experiência verificavam a resposta de cada aluno, contabilizando os acertos à pontuação de seu grupo. Ao final, foi divulgada a pontuação de cada grupo e o de maior pontuação foi premiado com uma caixa de chocolate.

d) Reunião pós-experiência: foi realizado um brainstorm, onde foi destacada a reação positiva dos alunos e os resultados que eles obtiveram. Nesse momento, também foram levantados alguns requisitos e consolidada a plataforma da aplicação. Nesta reunião também foi relatado que, durante a experiência, um dos alunos respondeu errado a uma questão, enquanto os demais do seu grupo acertaram e, em decorrência, ele ficou triste. Podemos levantar a hipótese de que, embora a experiência tenha envolvido os alunos a ponto de eles não desejarem errar, a competitividade deve ser vista com cautela. 
VII Congresso Brasileiro de Informática na Educação (CBIE 2018)

Anais do XXIX Simpósio Brasileiro de Informática na Educação (SBIE 2018)

\subsection{Identificação dos requisitos do sistema}

Com base na realização das etapas anteriores, foi definido que, como as escolas possuem um laboratório de informática para uso pedagógico, o sistema deve ser desenvolvido para a plataforma web. Também foram definidos alguns requisitos, como:

1. o sistema deve permitir que o professor possa organizar as atividades em desafios semanais e em metas diárias;

2. o sistema deve permitir que o aluno possa refazer as atividades já concluídas, possibilitando revisar os conteúdos vistos;

3. o sistema deve permitir que o aluno, ao realizar atividades, receba um bônus;

4. o sistema deve permitir que o aluno possa personalizar seu personagem;

5. o sistema deve permitir a interação e discussão entre os alunos sobre as atividades realizadas.

\subsection{Definição dos pré-padrões}

Alguns dos pré-padrões definidos foram: a) filtro de mensagens no bate-papo, para evitar palavras inadequadas; b) criação da sequência de conteúdos pelo professor; e c) feedback ao professor quanto às estatísticas dos alunos nas atividades. Estes pré-padrões foram definidos a partir das necessidades relatadas pelos professores, visto que outros sistemas não apresentavam todas essas características. Um outro pré-padrão foi definido a partir da experiência de uso com os alunos: d) alerta para que uma resposta incorreta não frustre os alunos. Esse pré-padrão surgiu pela observação do aluno que, quando errou a questão e os demais do seu grupo acertaram, ficou triste (competitividade).

\subsection{Definição do projeto de interação}

Foi construído um protótipo do software, chamado English Kingdom. Foram utilizadas tecnologias web, tais como: HTML, CSS, JavaScript e PHP. A tela inicial da aplicação é mostrada na Figura 4 e explicada na próxima seção.

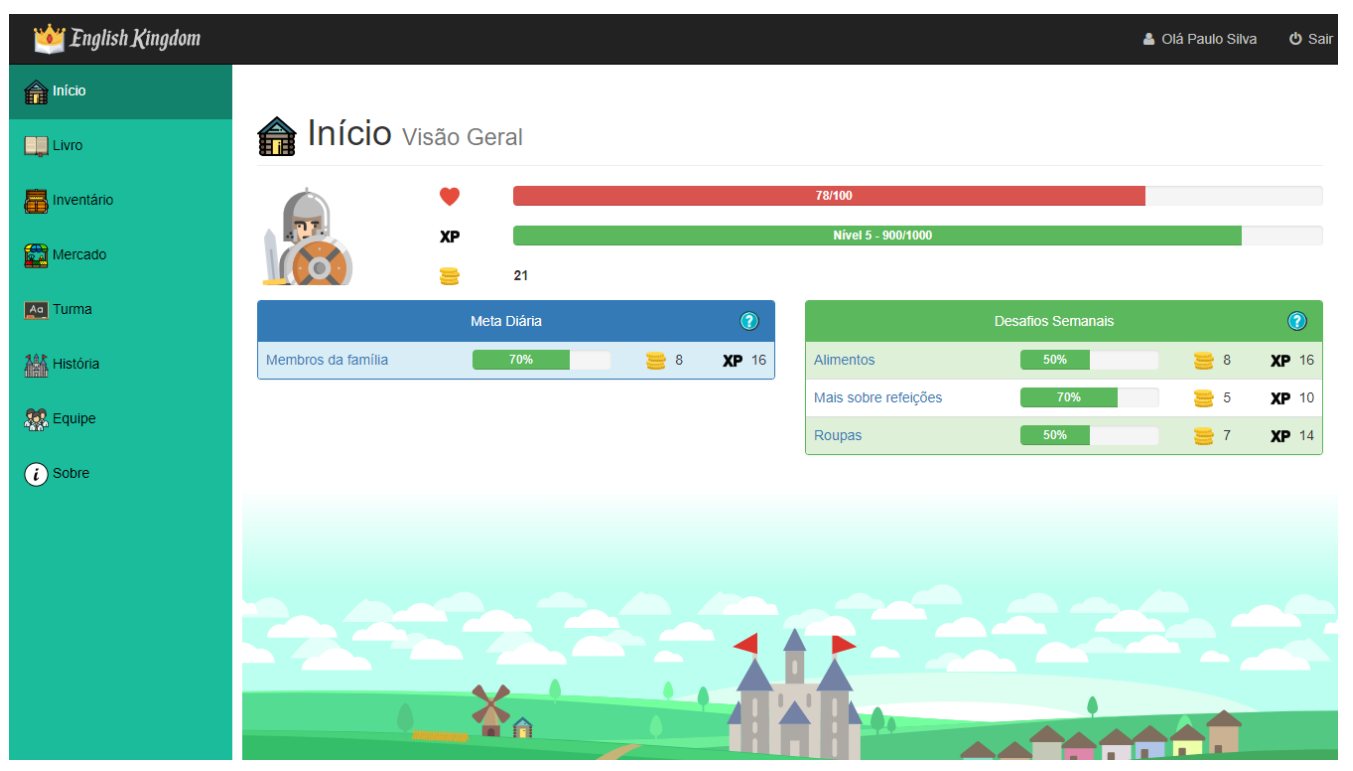

Figura 4. Tela inicial da aplicação 
VII Congresso Brasileiro de Informática na Educação (CBIE 2018)

Anais do XXIX Simpósio Brasileiro de Informática na Educação (SBIE 2018)

\section{English Kingdom}

O software projetado apresenta o seguinte contexto: um camponês viaja até um reino onde é falado um idioma que ele não conhece, mas um mago o ajuda a realizar as missões ensinando a língua daquele reino. À medida em que ele consegue realizar as missões, ele é recompensado com pontos de experiência e moedas virtuais, mas caso ele deixe de cumprir suas tarefas, ele é penalizado em pontos de vida. Um camponês pode se reunir em grupos a fim de derrotar um monstro da semana, resolvendo atividades propostas na aplicação. O protótipo desenvolvido pode ser acessado pelo link: http://englishkingdom.uxabilidade.com/.

Algumas das opções encontradas na aplicação são:

- "Livro": onde o usuário tem acesso a todas as atividades que já foram completadas ou não, sendo possível resolvê-las novamente;

- "Inventário": responsável por armazenar todos os itens presenteados ou adquiridos no mercado;

- "Mercado": onde fica disponível itens para compra, como roupas personalizadas, novos livros, espadas, arcos e acessórios que o usuário pode adquirir com as moedas obtidas na realização das atividades;

- "Turma": ambiente onde os alunos veem o que os demais estão fazendo na aplicação;

- "História": nesta seção, a cada atividade finalizada é adicionada uma pequena história relacionada aos acontecimentos do reino;

- "Equipe": onde os alunos de uma mesma equipe podem conversar e trocar ideias sobre os conteúdos.

\section{Avaliação do English Kingdom}

Para a validação do protótipo desenvolvido foi realizado um teste de usabilidade com crianças. De acordo com Rogers, Preece e Sharp (2013) o teste de usabilidade consiste em coletar dados relacionados a execução de tarefas no sistema. Estes dados podem ser obtidos a partir da gravação em vídeo do participante, pelo movimento do mouse, pelo pensamento quando expressado em voz alta, medidas quantitativas como tempo e número de atividades realizadas ou as observações dos observadores [Rogers et al. 2013]. Os objetivos da realização deste teste foram de identificar problemas de uso e novos requisitos, bem como verificar a aceitação de design pelas crianças.

Para a realização do teste, foram recrutados 5 alunos, com idades entre 6 e 10 anos, estudantes de uma escola pública do município de Russas - CE. Destes 5 alunos, 3 são alfabetizados e 1 pré-alfabetizado. Cada aluno recrutado recebeu previamente um termo de consentimento para que seu responsável autorizasse sua participação. Foi utilizado o seguinte cenário de uso: "Imagine que você está em uma aula de inglês e o seu professor pede para realizar uma atividade no English Kingdom.". Para a execução do teste foram necessárias três pessoas: um participante, um facilitador e um observador. O facilitador, além de ser responsável por conduzir o teste, também foi responsável por iniciar a gravação de áudio e vídeo das sessões. Já o observador, ficou responsável por realizar anotações relevantes durante a sessão.

O teste foi realizado da seguinte forma: no primeiro momento, foram dadas instruções e recolhido o termo de consentimento assinado. Foi esclarecido como seria condu- 
VII Congresso Brasileiro de Informática na Educação (CBIE 2018)

Anais do XXIX Simpósio Brasileiro de Informática na Educação (SBIE 2018)

zido o teste e que, a qualquer momento, o participante poderia pedir para encerrá-lo. Em seguida, o participante foi introduzido ao cenário de uso e convidado a realizar algumas tarefas, como: 1) verifique quantas moedas o personagem possui; 2) identifique qual o nível do personagem e se está próximo de subir seu nível; 3) verifique se há metas diárias, se sim, diga-me quais são; 4) verifique se há atividades concluídas, se sim, diga-me duas; 5) realize a atividade "Membros da família"; 6) diga-me com quais itens o personagem está equipado; 7) compre uma "Porção pequena de vida"; e por fim, 8) verifique qual a última ação executada pelo usuário João Thomaz. Ao final de cada sessão de teste, o participante respondeu a algumas perguntas, como: a) você gostou de usar o English Kingdom?; b) gostaria de usá-lo outra vez?; c) foi divertido utilizar o sistema? e; d) você achou difícil de usar?

Após a realização dos testes, os resultados foram contabilizados. O áudio e vídeo capturados foram utilizados para extrair informações sobre cada sessão. Um dos participantes pediu para encerrar o teste antes de concluí-lo. Os participantes do teste afirmaram ter gostado de utilizar o English Kingdom. Com exceção da criança que desistiu do teste, as demais gostariam de utilizá-lo outra vez e acham divertido utilizar. Contudo, três crianças afirmaram que o sistema é um pouco difícil de utilizar. Foram listadas as observações referentes a execução do teste. Dentre elas, destacam-se: problemas de design que ocasionaram dificuldades em identificar objetos de interação; o nome das funcionalidades no menu não está intuitivo para as crianças; as diversas telas do sistema, deixaram algumas crianças confusas ao utilizá-lo.

\section{Discussão}

Este trabalho procurou considerar os seguintes fatores:

a) importância de considerar o professor na construção do projeto do aplicativo: foram obtidos relatos de experiência e dificuldades enfrentadas no ensino que guiaram os projetistas na seleção de critérios que devem ser considerados em um sistema educativo. Apesar da participação de professores no desenvolvimento do projeto, eles não puderam estar tão presentes no processo de construção do design devido a sua disponibilidade, contudo, eles forneceram valiosas informações sobre os alunos, como: comportamentos, preferências, metodologias preferidas e etc.;

b) importância de considerar o aluno na construção do projeto do aplicativo: o contato com os alunos proporcionou o conhecimento de algumas informações a respeito do uso do sistema, como o seu ambiente físico (escolas públicas, laboratório de informática, computadores), social (interação entre alunos e com o professor em uma sala de aula) e cultural (nível de aprendizado). A experiência com os alunos também possibilitou observar como eles reagem a determinadas tarefas. Como as crianças puderam trabalhar juntas para atingir um objetivo, foram analisados fatores como: timidez, participação e competitividade;

c) o uso da metodologia: forneceu uma imersão no contexto do projeto do aplicativo, utilizando técnicas de IHC como: protótipos, cenários, experiência de uso, testes com usuários e pré-padrões. Com a metodologia os projetistas puderam ter um contato maior com os envolvidos (alunos e professores), conhecendo o ambiente de uso do software, bem como coletando dados que em um levantamento de requisitos poderiam não ser revelados, como a competitividade entre os alunos. 
VII Congresso Brasileiro de Informática na Educação (CBIE 2018)

Anais do XXIX Simpósio Brasileiro de Informática na Educação (SBIE 2018)

\section{Conclusão e trabalhos futuros}

$\mathrm{O}$ foco deste trabalho foi o projeto de um software educativo a partir de uma experiência de uso. Foi possível conhecer o contexto dos usuários durante o projeto e envolver alunos e professores. Apesar da avaliação ter sido realizada com poucas crianças, foi possível obter boas contribuições de design para a melhoria do projeto. Como trabalhos futuros, será feito o reprojeto do software, desenvolvimento e implantação no ambiente escolar. Em seguida, um estudo da apropriação da tecnologia deve ser feito a fim de acompanhar a inserção do software educativo no estudo de caso apresentado.

\section{Referências}

Abreu, C., Rosa, J., and Matos, E. (2017). Fantastic pirates: software de apoio ao ensino e à aprendizagem infantil. In Anais dos Workshops do Congresso Brasileiro de Informática na Educação, volume 6, page 252.

Chung, E. S., Hong, J. I., Lin, J., Prabaker, M. K., Landay, J. A., and Liu, A. L. (2004). Development and evaluation of emerging design patterns for ubiquitous computing. In Proceedings of the 5th Conference on Designing Interactive Systems: Processes, Practices, Methods, and Techniques, DIS '04, pages 233-242, New York, USA. ACM.

Cybis, W., Betiol, A., and Faust, R. (2015). Ergonomia e usabilidade: conhecimentos, métodos e aplicações, atualizada e ampliada. Novatec, SP.

Deliberato, R. (2016). Os benefícios do aprendizado de uma segunda língua na infância. Disponível em: https://goo.gl/JYCT1K. Acesso em 23 de jun de 2018.

Mendes, M. S. (2009). DF DIRCE-Design da Interação e levantamento de Requisitos com foco na Comunicação e Exploração de ideias: experiências de uso aplicadas em sistemas de criação de conteúdo para a televisão digital. PhD thesis, Dissertação de Mestrado (Mestrado em Informática Aplicada)-Universidade de Fortaleza (UNIFOR). 176f. Fortaleza.

Mendes, M. S. and Furtado, E. (2014). The dirce approach for requirements elicitation and design of interaction in innovative systems. In 2014 XL Latin American Computing Conference (CLEI), pages 1-10.

Nascimento, L., Oliveira, B., Lourenço, E., Sousa, J., and Monteiro, I. (2017). Storyteller: uma solução digital para a aprendizagem divertida da língua inglesa usando histórias infantis. In Anais estendidos do XVI Simpósio Brasileiro sobre Fatores Humanos em Sistemas Computacionais (IHC 2017).

Rogers, Y., Sharp, H., and Preece, J. (2013). Design de Interação. Bookman Editora.

Santana, V. and Ferreira, R. (2017). Desenvolvimento de games na língua inglesa: lógica e criatividade na construção do conhecimento. In Anais dos Workshops do Congresso Brasileiro de Informática na Educação, volume 6, page 414.

Toledo, B. d. S. (2015). O uso de softwares como ferramenta de ensino-aprendizagem na educação do ensino médio/técnico no instituto federal de minas gerais. Projetos e Dissertações em Sistemas de Informação e Gestão do Conhecimento, 4(2).

Tomlinson, B. J., Batterman, J., Chew, Y. C., Henry, A., and Walker, B. N. (2016). Exploring auditory graphing software in the classroom: The effect of auditory graphs on the classroom environment. ACM Trans. Access. Comput., 9(1):3:1-3:27. 